REMOTE SENSING ENABLING TECHNOLOGIES FOR ASSESSMENT OF CONSTRUCTION WORKER'S MUSCULOSKELETAL DISORDER RISKS: A REVIEW AND FUTURE EXTENSION

\author{
*Fei Dai ${ }^{1}$ and Xiaopeng Ning ${ }^{2}$ \\ ${ }^{I}$ West Virginia University \\ Department of Civil and Environmental Engineering \\ P.O. Box 6103, Morgantown, WV 26506, USA \\ (*Corresponding author: fei.dai@mail.wvu.edu) \\ ${ }^{2}$ West Virginia University \\ Department of Industrial and Management Systems Engineering \\ P.O. Box 6070, Morgantown, WV 26506, USA
}




\title{
REMOTE SENSING ENABLING TECHNOLOGIES FOR ASSESSMENT OF CONSTRUCTION WORKER'S MUSCULOSKELETAL DISORDER RISKS: A REVIEW AND FUTURE EXTENSION
}

\begin{abstract}
Musculoskeletal disorders (MSDs) are a group of painful disorders that affect muscles, tendons, nerves, joints, cartilage, and ligaments. They are a serious problem among the workforce in the United States. In the construction industry, high physically demanding tasks expose construction workers to a number of well recognized MSDs risk factors such as repetitive motion, high force exertion, and awkward body posture. Finding ways to effectively identify and evaluate risks of MSDs can significantly alleviate this problem. To this end, this paper reviews state of practice and research in the assessment of risks of MSDs among construction workers, in which a number of biomechanical models have been developed to evaluate joint and tissue loading with the aid of state-of-the-art remote sensing technologies. Findings from the review reveal that despite the advances in tracking human motion and muscle activities, current remote sensing approaches still involve sophisticated instrumentation and expensive experiment setup. These factors greatly limited the applicability of such approaches in real construction settings. How can we detect and evaluate the construction worker's MSDs risk in real work environments? In this paper, strategies by utilizing video surveillance systems are presented, to set the stage for addressing the above question and discussing future research in real-time, marker-less, and costeffective MSDs risk assessment.
\end{abstract}

\section{KEYWORDS}

Ergonomics, musculoskeletal disorders, construction workers, safety, image-based methods

\section{INTRODUCTION}

Musculoskeletal disorders (MSDs) are a serious problem among the workforce in the United States. In the construction industry, high physically demanding tasks expose construction workers to a number of well recognized MSDs risk factors such as repetitive motion, high force exertion, and awkward body posture. Thus far, a high incidence rate (i.e., 16 cases per 1000) of MSDs has been discovered among the population of construction workers. This problem can be even more severe because the above statistics does not cover the unreported cases and ones that do not cause loss of workdays. Considering the construction industry employs a population of 5.5 million which accounts for $4 \%$ of the entire U.S. workforce, tremendous losses can occur to both injured workers and contractors. The cost to the public is also significant: the U.S. workers' compensation for occupational injuries and illnesses covers less than $25 \%$ of their total cost and the rest is shared by the society. Finding ways to effectively identify and evaluate risks of MSDs can significantly alleviate this problem. To this end, this paper reviews state of practice and research in the assessment of risks of MSDs among construction workers, in which a number of biomechanical models have been developed to evaluate joint and tissue loading with the aid of state-of-the-art remote sensing technologies. Findings from the review reveal that despite the advances in tracking human motion and muscle activities, current remote sensing approaches still involve sophisticated instrumentation and expensive experiment setup. These greatly limit the applicability of these approaches in real construction settings. How can we detect and evaluate the construction worker's MSDs risk in real work environments? In this paper, strategies by utilizing video surveillance systems are presented, to set the stage for addressing the above 
question and discussing future research in real-time, marker-less, and cost-effective MSDs risk assessment.

The remainder of the paper is organized as follows. First, the characteristics and causes of MSDs are introduced, and the severity of such disease is analyzed. Then, a detailed review is provided in summarizing ergonomic measures taken in the construction industry and state-of-theart in identifying and assessing the risks associated with occurrence of MSDs. These are followed by the elaboration of a novel framework proposed by the authors, attempting to utilize the video surveillance system for assessing risks of MSDs among construction workers on site. Last, future work is discussed.

\section{IMPORTANCE OF RESEARCH}

MSDs, also known as cumulative trauma disorders, repetitive strain injuries, repetitive motion disorders, overuse syndrome, are a group of painful disorders of soft tissues (i.e., muscles, tendons, nerves, joints, cartilage, and ligaments). Symptoms of such disease include pain, aching, discomfort, numbness, tingling, and swelling that normally incur on the back, shoulders, neck, legs, wrists, fingers, elbows, and arms of a human body. Based on the cause of injury, MSDs can be categorized into sprains and strains, and cumulative trauma disorders (Inyang, Al-Hussein, ElRich, \& Al-Jibouri, 2012). Sprains and strains are injuries in joints or muscular tears, caused by high levels of forces that take place at a single event of lifting, lowering, pushing, pulling, or carrying. In such event, the physical forces exerted by a worker are beyond his/her physiological capability. The other type of MSDs is cumulative trauma disorders resulting from performing a task repetitively, even if the load is relatively small (i.e., repetitive motions such as bricklaying), or where a worker's body in a position is less than comfortable (i.e., awkward body postures such as tying rebar) (HSE, 2012). Most common MSDs among construction workers are carpal tunnel syndrome, tendonitis, tennis elbow, trigger finger, sciatica, herniated discs and low back pain (Connecticut DPH, 2012; NIOSH, 2007). Tasks associated with MSDs include, but are not limited to, lifting and carrying heavy objects, laying blocks, handling pipework, laying kerbs, paving slabs, installing plasterboards, and installing mechanical and electrical (M\&E) equipment at height. Construction workers who suffer from MSDs may have a reduced ability on work, with pain or discomfort, or in most serious cases, have the permanent disability (NIOSH, 2007).

Work-related MSDs account for 33\% of all occupational injuries and illnesses that require days away from work in U.S. (data as of 2011, BLS, 2012a). In the construction industry, the high physically demanding tasks expose construction workers to tremendous recognized risk factors such as constantly repeated motions, high levels of forces, and awkward body postures (Kisner \& Fosbroke, 1994; NIOSH, 2012), which leads to a high incidence rate (i.e., 16 cases per 1000) of MSDs among workers in this industry (BLS, 2012a). This incident rate is even higher for the state of West Virginia where the study is being carried out, grounded on a statistic that 22 MSDs cases occurred per 1000 workforces (data as of 2010, BLS 2012b) which was 34\% higher than the national rate. Note that the above MSDs statistics are publically recorded and therefore conservative. They do not include those unreported and cases that do not cause loss of workdays. A recent study (Boschman et al., 2012), in which 1500 construction professionals and workers were randomly selected and surveyed, revealed that symptoms of MSDs in the construction industry can reach an incidence rate as high as 67 percent (i.e., $67 \%$ for bricklayers, and $57 \%$ for supervisors), further reflecting the severity of the MSDs disease that takes place in the construction industry. 
The premium cost of work compensation insurance that contractors normally purchase is higher than most industries (WCRC, 2012). One insurer reported that 29\% of insured contractors' workers' compensation claims were due to MSDs (NIOSH, 2006). In addition to these direct costs, contractors may incur a variety of indirect costs including but are not limited to, wages paid to injured workers for absence, cost related to time lost due to work stoppage, and employee training and replacement cost (OSHA, 2012). Considering that the construction industry employs a population of 5.5 million accounting for $4 \%$ of the U.S. workforce (BLS, 2012c), MSDs to construction workers can engender problems that impact the regional or national economy. Based on the findings by (Leigh, 2011), the U.S. workers' compensation for occupational injuries and illnesses covers less than $25 \%$ of their total cost; it therefore caused the rest being shared by the society. This problem may cascade further, since it is expected that there is going to be short of skilled workers needed to construct our nation's facilities in the market in the following three to five years (McGraw-Hill Construction, 2012). Any efforts towards ameliorating the construction workforce safety and health condition will reduce the percentage of work compensation being spent and, considering that construction is an $\$ 872$ billion industry (Census Bureau, 2012), each $1 \%$ of improvement can lead up to $\$ 872$ million in savings.

\section{STATE OF PRACTICE IN CONSTRUCTION ERGONOMICS}

Thus far, efforts on construction MSDs risk management have been primarily focused on two aspects: 1) promoting workplace ergonomic practice (e.g., Ohio BWC, 2012; North Carolina DL, 2012), and 2) providing safety trainings (e.g., NIOSH, 2007; OSHA, 2012; Hoe et al., 2012). These efforts are useful but received limited effects: although investments in ergonomic practice and safety trainings have been increasing annually, the incidence rate due to MSDs has not seen decrease accordingly (BLS, 2011; 2012a). The major reason, the authors believe, is that current construction projects entail a sheer volume of manual, tedious and repetitive processes, leading to existing management efforts still unable to effectively control and eliminate the potential MSDs risks. Moreover, industry and authorities have attached more importance to fatal accidents such as falls, cut, and burning. To the best knowledge of the authors, very few measures have been taken for the daily construction activities to ensure rigorous assessment of ergonomic risks and therefore prevent possible occurrence of MSDs.

\section{STATE OF RESEARCH IN CONSTRUCTION MUSCULOSKELETAL DISORDER RISK ASSESSMENT}

Construction scholars lack ergonomic knowledge and therefore it is difficult for them to address the MSDs problem solely. In the fields of industrial and medical engineering, researchers have been working on MSDs prevention and mitigation for decades, mainly focusing on risk identification and assessment in relation to awkward posture, repetitive motion, and high force exertion as main factors directly impacting occurrence of MSDs, and intervention development for providing new instrumentation or enabling redesign to change the way a high risk task is carried. Generally, methods involved in MSDs risk assessment can be categorized into 1) survey, 2) expert observation, 3) direct measurement, and 4) advanced sensing techniques, all of which will be discussed in detail in the following.

\section{Survey}

Self-reported survey was initially developed to assess the work-related MSD problems. It is carried out primarily in the form of questionnaire administration and face-to-face interviews. A 
number of questionnaires and surveys have been developed to assess musculoskeletal symptoms in occupational settings. Nordic Musculoskeletal Questionnaire was first developed in the 1980's (Kuorinka et al., 1987) and widely used in Ergonomics studies (Aarås et al., 1998; Kucera et al., 2009; Reme et al., 2012). The Borg Scale is a rating scale that designed to evaluate the perceived levels of physical exertion (Borg, 1970; 1982). It was used in a large number Ergonomics studies to assess work exposure (Vieira et al., 2006; Jones \& Kumar, 2010; Li \& Yu, 2011). One study that investigated ergonomics issues in the office environment was the development of Job Requirements and Physical Demands Survey (JRPDS) by the U.S. Air Force (Dane et al., 2002). In the construction industry, Task Analysis methodology (Silverstein, 1985) was used to develop a survey to quantify the perceived injury risk of various site tasks such as painting, hammering nails (Killough and Crumpton, 1996).

The advantage of the survey methods is that subjects can report issues and problems that are difficult to observe (e.g., pain and perceived workload). The downside of these methods is that the results are based on subjective assessment and thus can vary significantly among individuals. Also, the survey responses can be biased due to personal implications, undermining the reliability of these methods in comparison to other methods such as direct measurement and advanced sensing techniques (Spielholz et al., 2001; Jones \& Kumar, 2010).

\section{Expert Observation}

To assess the risk of MSDs on site, a number of observational tools have been developed, allowing experts to record and evaluate on a set of structured variables (e.g., a checklist with questions for different body regions) in relation to evaluation of risk factors. One early observation tool was the Ovako Working Posture Analyzing System (OWAS), first introduced by a steel company from Finland in 1973 (Karhu et al., 1977). The OWAS evaluated the MSD risk level of different body segments (back, arms and legs) by assessing postures of workers during their task performance. Based on OWAS, Buchholz et al. (1996) developed an enhanced tool named PATH (Posture, Activity, Tools, and Handling) and used it in the work risk assessment of highway construction workers. In comparison to OWAS, PATH not only evaluated the working postures, but also included descriptions of worker's activity, tool usage, load handling, and types of grasp in evaluation. The Rapid Upper Limb Assessment (RULA) is another observational tool developed to assess the risk of work-related upper limb disorders (McAtamney \& Corlett, 1993). RULA was also used in investigating corresponding ergonomics designs. More recently, a whole body postural analysis tool called Rapid Entire Body Assessment (REBA) was developed mainly focusing on analyzing unpredictable working postures a worker employs in the health care and service industries (Hignett \& McAtamney, 2000).

These observational tools are widely used in field studies and advantageous in: 1) minimal disturbance to worker task performance, allowing for tasks in real settings to be assessed, and 2) experts' visit with minimal instrumentation leading to cost effectiveness for field investigations. However, expert observational tools have to rely on experts' visit and their subjective evaluation. The limitation is that the assessment cannot be performed continuously and only limited number of jobs can be assessed during experts' visit. In addition, the inter-rater differences may result in disagreement in the results of their evaluations.

\section{Direct Measurement (Lab Assessment)}

In achieving objective assessment, a class of direct measurement methods was developed, among which sensors such as goniometers, inclinometers, optical scanners, electromagnetic, and sonic sensors were used as the key instrumentation in analyzing human body biomechanics. For 
these sensors, markers are attached directly to specific anatomic points on the human subject for measuring their exposure variables at work. Three-dimensional (3D) coordinates of all body markers can be recorded in real time by using dedicated computing algorithms to track the position and angular movement of different body segments (Li \& Buckle, 1999). The posture and motion variables will then be worked on with the biomechanical models to evaluate joint and tissue loadings. One example was the Lumbar Motion Monitor (LMM) developed by Marras et al. (1992), in order to assess worker's risk of low back injury in the work place. This system was primarily equipped with triaxial electronic goniometer and was capable of recording a worker's 3D thoracolumbar spine motion during the performance of different manual material handling tasks. Following this, the same research group investigated the characteristics of trunk motion during the performance of repetitive manual material handling with the aid of LMM (Marras \& Granata, 1997). Another example was the Physical Status Monitor proposed by Gatti et al. (2010) to monitor physiological parameters of construction workers such as heart rate. The idea was that combined with environmental conditions such as temperature and humidity, the physiological parameters can be used to estimate physical strain of the site crew. Also, to address shoulderrelated MSDs among the construction workforce, an External Musculoskeletal Joint Angle sensor system was developed by Alwasel et al. (2011). The system tracks the worker upper arm motion using magneto-resistive angle sensors. As the relative angle between a moving arm frame and a reference torso frame is measured, the predefined awkward shoulder postures can be detected. In addition, Cheng et al. (2013) put forth an effort on fusing technologies of Physiological Status Monitoring (for collecting heart rate and thoracic bending angle) and location sensing (i.e., UWB) for localizing ergonomically unsafe behaviors of heavy load lifting tasks.

In general, the accuracy of applying direct measurement is high, and post-processing data collected by the instrument is relatively simple. However, most of direct measurement systems require sophisticated instrumentation and laboratory (indoor) environment to collect body motion and muscle activity data (McGill \& Norman 1986; Kingma et al., 1996; Marras \& Granata 1997). The body-attached markers may also interfere with the workers' behavior and undermine the performance of regular activities on site. In addition, direct measurement requires considerable initial investment on equipment, and the resources needed to maintain and employ highly trained and skilled technical staff to ensure their effective operation are expensive (David, 2005). In summary, direct measurement is suitable for lab assessment, in observation of characteristics of risky postures, motions, investigating injury causes, and understanding how injury develops. For continuous monitoring and estimation of in-situ workers MSD risks, direct measurement is bound to its constraints of functioning properly in real workplace.

\section{Advanced Sensing Techniques}

Advanced sensing techniques concern marker-less sensor based biomechanics, in which range imaging sensors or video cameras are utilized to acquire human movement footage and estimate join loadings based on the whole body kinematics. These techniques do not need human subjects to be directly attached with markers or signal receivers (Chang et al., 2003; Coenen et al., 2011). Therefore, they are viable for assessment in real workplaces. To analyze complex and dynamic human motions, 3D sensing technologies were developed using range imaging sensors such as Microsoft Kinect (Warade et al., 2012; Wang et al., 2012). In these methods, the range imaging sensors are used to collect depth of each image pixel inside the device to its corresponding location in the scene. Based on the depth values, human body segments and joints are subsequently detected and tracked. Specifically, in the construction industry, the Kinect range camera was used to detect and classify worker postures (a worker is standing, bending, sitting, or crawling) in categorizing activities as ergonomic or non-ergonomic for the training purpose (Ray 
\& Teizer, 2012); and Han et al. (2013) applied Kinect to collect depth map in order to generate motion data of site workers and inspect their unsafe behavior in climbing ladders. Range sensor data is relatively easy to be processed in the post-processing phase. Nevertheless, range sensor has the downside of being applicable only within the range of $5 \mathrm{~m}$ and unreliable in outdoor environments. Thus, it is not appropriate to apply this technology to large scale workspaces such construction site. In terms of utilization of video surveillance, the research work is still at infant stage. At current stage, two dimensional (2D) images were collected to record human motions and obtain kinematic data (e.g., joint angle, body segment acceleration) by manually identifying the location of human joint centers from each frame (Solomonow et al., 2003; Chang et al., 2003; Coenen et al., 2011). While the optical sensing technique is suitable for both indoor and outdoor settings, the procedure involved thus far has been only suitable for simple and symmetrical motions that can be fully described in a single plane. Currently, video-based methods are not considered fully automatic because they still rely on manual input in determining the posture and joint angles for estimation of joint loadings. Instead of computing joint loadings, researchers also attempted to apply training models of motions as a benchmark to compare with human skeleton models extracted from videos (Han et al. 2012). The purpose was to analyze safety behaviors of site workers in a statistical way. The accuracy of analysis results not only relies on the geometric skeleton model extracted, but the training model and comparison scheme also impact the analysis performance as well.

To sum up, for outdoor construction worker health study, remote sensing techniques are promising. Yet, there is much to be desired in that post-processing the data contained in the videos from the unstructured format to informative knowledge is still challenging.

\section{PROBLEM STATEMENT AND OBJECTIVE}

While self-reported survey and expert observational tools are easy and inexpensive to implement, data collected by these tools are subjective, inter-rater unreliable, and the results can be error-prone. Direct measurement can provide more objective results; however, this technique requires sensors or markers to be directly attached on human subjects and therefore is not suitable to be used in real construction settings. Though advanced remote sensing technologies hold great potential to remove the above mentioned hurdles, they are still involved with manual procedures, and therefore inconvenient for use in construction safety management applications. There is a need for more automated remote sensing technologies, which are able to collect construction workers' ergonomic data and monitor their MSDs risk in the daily work activities.

Considering surveillance camera being commonly used in construction site, the objective of this research is to create a video based risk assessment method that can assess the risk of MSDs objectively, automatically, and continuously with the use of surveillance system on site. An automatic process will be highly favorable to estimate the joint angle and body segment motion pattern and provide timely feedback.

\section{PROPOSED FRAMEWORK}

Figure 1 presents the main workflow of the proposed method. The premise is that the video surveillance is able to "see" the site workers. The technical details of the proposed method are presented in the following steps.

First, detection of body motions of the site workers is performed using machine vision techniques, comprising: initialization, tracking and pose estimation. Initialization of vision-based human motion capture usually requires definition of a humanoid model to characterize the shape, appearance, kinematic structure and initial pose of the object to be tracked (Moeslund et al. 2006). 


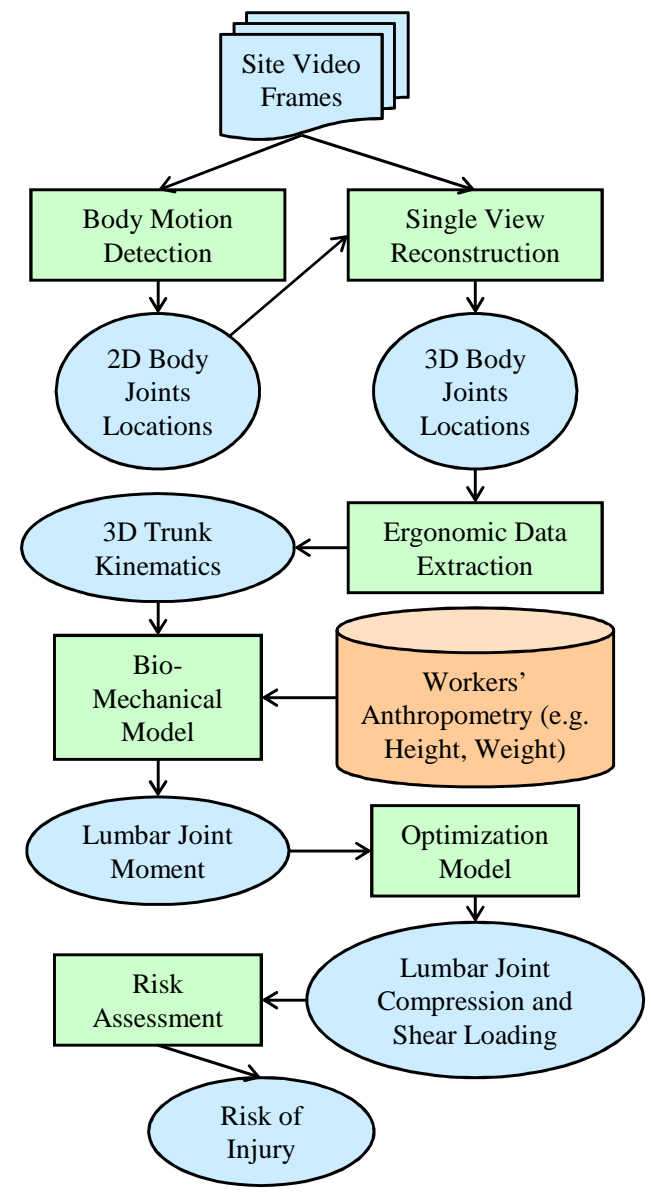

Figure 1: Methodology workflow

In contrast to other personnel, site workers can be denoted as persons who wear safety gears (e.g., safety vest, hard hat) (Park \& Brilakis 2012). As site workers changes poses in performing their jobs, blob extraction, histograms of oriented gradients and color histograms can be applied to detect the site workers' foreground map in video frames. This is followed by the tracking of the workers. During the tracking process, the detected workers in the current frame will be associated with those in the previous frames, resulting in a temporal trajectory through the image space. Pose estimation is the process of detecting body joint positions or body segments of a human in the resulting regions of the video frames. This can be achieved typically by applying two classes of methods, namely, exemplar based and model based methods. The detected joint locations are in 2D scope. Given that the surveillance camera's location (3D position and orientation) is known, the 3D joint locations are then estimated using single view reconstruction. From single view reconstruction, 3D locations of at least ten (neck, lumbosacral joint, shoulder (bilateral), wrists (bilateral), knee (bilateral) and ankle (bilateral)) joints are obtained. Based on these joint locations, the trunk flexion angle is calculated and the body segment (head, trunk, arm, leg) centers of mass (COM) are estimated in each frame. Next, the linear and angular velocity and acceleration of each body segment COM with respect to the lumbosacral joint are calculated. In order to estimate spinal (lumbosacral joint) loading, the instantaneous lumbar joint moment is calculated with the 3D ergonomic data. The equation in (Ning \& Guo 2012) provides the procedure of calculating lumbar joint moment, in which a total number of $n$ body segments including trunk, left arm, right arm, left hand load, and right hand load are considered. Variables 
of the linear acceleration, angular acceleration, total mass of the $i$ th segment, the horizontal distance between the COM of segment $i$ to the lumbar joint are used to solve the equation. The next is to estimate lumbar joint loading in which lumbosacral joint compression and shear forces are estimated. The magnitude of spinal compression and shear forces are highly associated with the risk of low back injury. They are determined by the weight of the trunk as well as forces exerted from all trunk tissues (e.g., muscles, ligaments). However, without empirical measurements of lumbar tissue forces, it is not feasible to calculate spinal compression forces due to the redundancy in equations (i.e., there are more unknown tissue forces than equilibrium equations). To obtain spinal compression and shear forces with the use of only trunk anthropometric and kinematics data, optimization models were developed. A well-established double-objective function optimization model (Bean et al. 1988) can be used in estimating lumbar tissue forces and thereby the lumbosacral joint compression and shear forces. In this study, both acute and cumulative (long term) LBD risks are considered. Waters et al., (1993) identified the maximum acceptable spinal compressive force of $3400 \mathrm{~N}$. This value is used as a criterion in finding highly risky tasks that could cause acute back injury. To address cumulative risk of injury, an existing risk assessment tool - NIOSH lifting equation (Waters et al. 1993) can be adopted. As an output of the proposed method, the lifting index calculated using the NIOSH lifting equation will be used to categorize the level of cumulative LBD risks.

\section{FUTURE WORK}

While assessing risk of MSDs injury among construction site workers using video surveillance presents great potentials for its cost-effectiveness and ease of implementation on construction site, substantial work is still needed to expand the framework into a practical solution. Particularly, efforts needed on this regard will include validation and expansion of the machine vision and development of biomechanical models. The former aims at automatic estimation of worker motions whereas the latter targets accurate evaluation of spinal forces and thereby enabling reliable risk assessment of MSDs. In addition, procedures will be designed to evaluate whether human joint angle and body segment locations generated by the surveillance system will demonstrate reasonable accuracy and consistency when compared to benchmark. In this study, the benchmark will be an eight camera (MX-13) 3D optical motion capture system (Vicon) that is capable of capturing whole body kinematics. The implemented assessment models will be tested through comparison with ground reaction moment (recorded by force plate) to estimate joint moment through a well-established inverse dynamic model.

\section{CONCLUSIONS}

MSDs are a serious problem among the construction workforce in the U.S. They can cause temporary or even permanent disability, which may affect the worker's earnings and the contractor's profits, and thereby lead to severe loss of the society. This paper reviewed and summarized recent research efforts in assessment and estimation of this disease. This was followed by a presentation of a different method proposed by the authors. The method concerns utilization of the video surveillance, together with a biomechanical model, to estimate the risk of MSDs that take place on construction sites. Nevertheless, there are a number of tasks remaining, which primarily focuses on the validation and expansion of the machine vision technique for pose estimation and development of biomechanical models for risk evaluation. Accuracy and consistency of the human joint angle and body segment locations generated by the method also need to be evaluated. These will be the future work of this study. 


\section{REFERENCES}

Aarås, A., Horgen, G., Bjørset, H. H., Ro, O., \& Thoresen, M. (1998). "Musculoskeletal, visual and psychosocial stress in VDU operators before and after multidisciplinary ergonomic interventions." Applied ergonomics, 29(5), 335-354.

Bean, J.C., Chaffin, D.B., and Schultz, A.B. (1988). "Biomechanical model calculation of muscle contraction forces: A double linear programming method." J. Biomechanics, 21, 59-66.

Borg, G. (1970). "Perceived exertion as an indicator of somatic stress." Scandinavian journal of rehabilitation medicine, 2(2), 92-98.

Borg, G. (1982). "Psychophysical bases of perceived exertion." Medicine and Science in Sports and Exercise, 14(5), 377-381.

Boschman, J.S., van der Molen, H.F., Sluiter, J.K., \& Frings-Dresen, M.H. (2012). "Musculoskeletal disorders among construction workers: a one-year follow-up study." BMC Musculoskeletal Disorders, 13:196.

Buchholz, B., Paquet, V., Punnett, L., Lee, D., \& Moir, S. (1996). "PATH: A work samplingbased approach to ergonomic job analysis for construction and other non-repetitive work." Applied Ergonomics, 27(3), 177-187.

Bureau of Labor Statistics. (2011). "Nonfatal occupational injuries and illnesses requiring days away from work, 2010." <www.bls.gov/news.release/archives/osh2_11092011.pdf>.

Bureau of Labor Statistics (BLS). (2012a). "Nonfatal occupational injuries and illnesses requiring days away from work, 2011." <www.bls.gov/news.release/archives/osh2_11082012.pdf> (Nov. 10, 2012).

Bureau of Labor Statistics (BLS). (2012b). "Musculoskeletal disorders by nature of injury or illness, West Virginia."<ftp.bls.gov/pub/special.requests/ocwc/osh/wv2010_nature.pdf>.

Bureau of Labor Statistics (BLS). (2012c). "B-1. Employees on nonfarm payrolls by major industry sector, 1962 to date." Establishment Data Historical Employment, <www.bls.gov/opub/ee/2012/ces/tableb1_201206.pdf > (Nov. 12, 2012).

Census Bureau (2011). "December 2012 Construction at $\$ 885.0$ Billion Annual Rate" <http://www.census.gov/const/C30/release.pdf > (Feb. 24, 2013).

Chang, C.C., Hsiang, S., Dempsey, P.G., \& McGorry, R.W., (2003). "A computerized video coding system for biomechanical analysis of lifting tasks." International Journal of Industrial Ergonomics, 32(4), 239-250.

Cheng, T., Migliaccio, G.C., Teizer J., Gatti, U.C. (2013). "Data Fusion of Real-time Location Sensing (RTLS) and Physiological Status Monitoring (PSM) for Ergonomics Analysis of Construction Workers", Journal of Computing in Civil Engineering (in press)

Coenen, P., Kingma, I., Boot, C.R.L., Faber, G.S., Xu, X., Bongers, P.M., \& Van Dieen, J.H. (2011). "Estimation of low back moments from video analysis: a validation study." Journal of Biomechanics, 44(13): 2369-2375.

Connecticut Department of Public Health. (2012). Fact sheet - construction work and cumulative trauma disorders. Retrieved on November 10, 2012, from http://www.ct.gov/dph.

David, G.C. (2005). "Ergonomic methods for assessing exposure to risk factors for work-related musculoskeletal disorders". Occupational Medicine, 55:190-199.

Dane, D., Feuerstein, M., Huang, G.D., Dimberg, L., Ali, D., \& Lincoln, A., (2002). "Measurement properties of a self-report index of ergonomic exposures for use in an office work environment." J. Occupational and Environmental Medicine. 44(1): 73-81.

Gatti, U. C., Migliaccio, G. C., Schneider, S., \& Fierro, R. (2010). "Assessing physical strain in construction workforce: A first step for improving safety and productivity management." Proceedings of the 27th ISARC, pp. 255-264, Bratislava, Slovakia. 
Han, S., Lee, S., \& Peña-Mora, F. (2012) Vision-Based Motion Detection for Safety Behavior Analysis in Construction. Construction Research Congress 2012, pp. 1032-1041.

Han, S., Lee, S., \& Peña-Mora, F. (2012). "Vision-based detection of unsafe actions of a construction worker: a case study of ladder climbing." J. Comput. Civ. Eng., in press.

Health and Safety Executive (HSE). (2012). Musculoskeletal disorders. Retrieved on December 9, 2012, from http://www.hse.gov.uk/construction/healthrisks/msd.htm.

Hignett, S., \& McAtamney, L. (2000). "Rapid entire body assessment." Applied Ergonomics, 31(2), 201-205.

Hoe, V.C., Urquhart, D.M., Kelsall, H.L., and Sim, M.R. (2012). "Ergonomic design and training for preventing work-related musculoskeletal disorders of the upper limb and neck in adults." Cochrane Database of Systematic Reviews, 8, John Wiley \& Sons, Ltd.

Inyang, N., Al-Hussein, M., El-Rich, M., \& Al-Jibouri, S. (2012). "Ergonomic analysis and the need for its integration for planning and assessing construction tasks." J. Constr. Eng. Manage., 138(12), 1370-1376.

Jones, T., \& Kumar, S. (2010). "Comparison of ergonomic risk assessment output in four sawmill jobs.” Intl. J. Occupational Safety and Ergonomics, 16(1), 105-111.

Karhu O., Kansi P., \& Kuorinka I. (1977). "Correcting working postures in industry: A practical method for analysis." Applied Ergonomics, 8(4), 199-201.

Killough, M.K., \& Crumpton, L.L. (1996). "An investigation of cumulative trauma disorders in the construction industry." Intl. J. Industrial Ergonomics, 18(5-6), 399-405.

Kingma, I., de Looze, M.P., Toussaint, H.M., Klijnsma, H.G., \& Bruijnen, T.B.M. (1996). "Validation of a full body 3-D dynamic linked segment model." Human Movement Science, 15, 833-860.

Kisner, S. \& Fosbroke, D. E. (1994). "Injury hazards in the construction industry." Journal of Occupational Medicine, 36: 137-143.

Kucera, K.L., Loomis, D., Lipscomb, H.J., Marshall, S.W., Mirka, G.A., \& Daniels, J.L. (2009). "Ergonomic risk factors for low back pain in North Carolina crab pot and gill net commercial fishermen." Am J Ind Med, 52(4), 311-321.

Kuorinka, I., Jonsson, B., Kilbom, A., Vinterberg, H., Biering-Sorensen, F., Andersson, G., \& Jorgensen, K. (1987). "Standardised Nordic questionnaires for the analysis of musculoskeletal symptoms." Applied Ergonomics, 18(3), 233-237.

Leigh, J.P. (2011). "Economic burden of occupational injury and illness in the United States." Milbank Quarterly, 89(4), 728-772.

Li, G., \& Buckle, P. (1999). "Current techniques for assessing physical exposure to work-related musculoskeletal risks, with emphasis on posture-based methods." Ergon., 42:674-695.

Li, K.W., \& Yu, R. (2011). "Assessment of grip force and subjective hand force exertion under handedness and postural conditions." Applied Ergonomics, 42(6), 929-933.

Marras, W.S., Fathallah, F., Miller, R.J., Davis, S.W., \& Mirka, G.A. (1992). "Accuracy of a Three Dimensional Lumbar Motion Monitor for Recording Dynamic Trunk Motion Characteristic." International Journal of Industrial Ergonomics, 9(1), 75-87.

Marras, W.S., \& Granata, K.P. (1997). "The development of an EMG-assisted model to assess spine loading during whole-body free-dynamic lifting." Journal of Electromyography and Kinesiology, 7: 259-268.

McAtamney, L., \& Corlett, E.N. (1993). "RULA - A survey method for the investigation of work-related upper limb disorders." Applied Ergonomics, 24(2), 91-99.

McGill, S.M., \& Norman, R.W. (1986). "Partitioning of the L4-L5 dynamic moment into disc, ligamentous, and muscular components during lifting." Spine, 11, 666-678. 
McGraw-Hill Construction. (2012). "Construction industry workforce shortages: role of certification, training and green jobs in filling the gaps." SmartMarket Report, <www.usgbc.org/ShowFile.aspx? DocumentID=18984 > (Nov. 12, 2012).

Moeslund, T. B., Hilton, A., \& Kru, V. (2006). "A survey of advances in vision based human motion capture and analysis." Comput. Vis. Image Under., 104(2), 90-126.

National Institute of Occupational Safety and Health (NIOSH). (2006). Proceedings of a meeting to explore the use of ergonomic interventions for the mechanical and electrical trades. Cincinnati, OH: U.S. Department of Health and Human Services, Centers for Disease Control and Prevention, (NIOSH) Publication No. 2006-119.

National Institute of Occupational Safety and Health (NIOSH). (2007). Simple Solutions Ergonomics for Construction Workers, http://www.cdc.gov/niosh/docs/2007122/pdfs/2007-122.pdf. (Nov. 14, 2012).

National Institute of Occupational Safety and Health (NIOSH). (2012). "Construction Safety and Health". Workplace Safety \& Health Topics. Retrieved November 9, 2012.

Ning, X., and Guo, G. (2013). "Assessing spinal loading using the kinect depth sensor: a feasibility study." IEEE Sensors Journal, 13(4), 1139-1140.

North Carolina Department of Labor. (2012). Sample program on "construction safety and health policy". <www.nclabor.com/osha/consult/sampleprograms/ConstructionS\&HPolicy.pdf>, accessed on November 14, 2012.

Occupational Safety and Health Administration (OSHA). (2012). White Paper on Injury and Illness Prevention Programs, <www.osha.gov/dsg/topics/safetyhealth/OSHAwhitepaper-january2012sm.pdf> (Nov. 15, 2012).

Ohio Bureau of Workers' Compensation. (2012). Ergonomics Best Practices for the Construction Industry, accessed on November 14, 2012, <www.ohiobwc.com/downloads/brochureware/publications/ConstSafeGrant.pdf $>$.

Park, M.W., and Brilakis, I. (2012). "Construction worker detection in video frames for initializing vision trackers." Autom. Constr., 28, 15-25.

Ray, S.J. and Teizer J. (2012). "Real-Time Construction Worker Posture Analysis for Ergonomics Training", Advanced Engineering Informatics, Elsevier, 26, pp. 439-455.

Reme, S. E., Dennerlein, J. T., Hashimoto, D., \& Sorensen, G. (2012). "Musculoskeletal pain and psychological distress in hospital patient care workers." Occup. Rehab., 22(4), 503-510.

Silverstein, B. A. (1985). The Prevalence of Upper Extremity Cumulative Trauma Disorders in Industry, Ph.D. Dissertation, University of Michigan, $198 \mathrm{pp}$.

Solomonow, M., Baratta, R.V., Banks, A., Freudenberger, C., \& Zhou, B.H. (2003). "Flexionrelaxation response to static lumbar flexion in males and females." Clinical Biomechanics, 18: 273-279.

Spielholz, P., Silverstein, B., Morgan, M., Checkoway, H., \& Kaufman, J. (2001). "Comparison of self-report, video observation and direct measurement methods for upper extremity musculoskeletal disorder physical risk factors." Ergonomics, 44(6), 588-613.

Vieira, E.R., Kumar, S., Coury, H.J.C.G., \& Narayan, Y. (2006). "Low back problems and possible improvements in nursing jobs." Journal of Advanced Nursing, 55(1), 79-89.

Wang, J., Liu, Z., Chorowski, J., Chen, Z., \& Wu, Y. (2012). "Robust 3D action recognition with random occupancy patterns." ECCV 2012, LNCS, 872-885.

Warade, S., Aghav, J., Claude, P., \& Udayagiri, S. (2012). "Real-time detection and tracking with Kinect." Intl. Conf. Comp. Info. Tech., Bangkok, 86-89.

Waters, T.R., Putz-Anderson, V., Garg, A., and Fine, L.J., (1993). "Revised NIOSH equation for the design and evaluation of manual lifting tasks." Ergonomics, 36(7), 749-776.

Workers Comp Resource Center. (2012). "Worker's compensation in the construction industry." <reduceyourworkerscomp.com/industry-construction.php\#axzz2C2a9D21K>, (11/11/12). 